\title{
Governance of Open Source Software Foundations: Who Holds the Power?
}

Ludovico Prattico

\author{
"The greater the power, the more dangerous the abuse." \\ Edmund Burke (1729-1797) \\ Politician, philosopher, and author
}

\begin{abstract}
The research reported in this article attempts to discover who holds the power in open source software foundations through the analysis of governance documents. Artificial neural network analysis is used to analyse the content of the bylaws of six open source foundations (Apache, Eclipse, GNOME, Plone, Python, and SPI) for the purpose of identifying power structures. Results of the research suggest that: i) the actions of an open source software foundation are centered around one of three groups: Members, Chairman/President/Executive Director, and Board of Directors; ii) in only one of the six foundations is the Board of Directors responsible for both the community and the product; and iii) artificial neural network analysis of the content of bylaws provides unbiased insights of the power structure of open source software foundations. These results may prove useful to those who contribute to open source foundations and use their products and services.
\end{abstract}

\section{Introduction}

Open source software foundations (OSSFs) create, enhance, and support open source technology such as tools, frameworks, operating systems, productivity software, and content management systems. These foundations act as keystones to anchor ecosystems of companies that generate revenue by developing and commercializing products based on the outputs produced by the foundations. Examples of OSSFs include the Apache Software Foundation (apache.org), which supports the Apache HTTP Server among many other projects, and the Eclipse Foundation (eclipse.org), which supports the Eclipse software development environment.

For foundations members, the benefits of OSSFs include: spreading development costs across participating members, increasing revenue generation through increased sales of complementary products, increasing the addressable market by competing more effectively across "technology stacks", and acting as a common good through which member firms increase their goodwill and general welfare (Riehle, 2010; tinyurl.com/ ac3fzob).
In order to guide their operations and achieve their objectives, OSSFs develop governance policies, or bylaws, in at least four areas:

\section{Board of Directors composition}

2. Foundation bylaws

3. Membership agreement

\section{Intellectual property rights}

Although researchers have studied OSSF governance from a variety of perspectives, few have examined OSSF governance based on studies of governance documents. The objective of this research is to answer the question: Where does the power lie in the governance of open source software foundations? The question is answered by examining the bylaws of not-for-profit, member-supported, OSSFs that are the keystone organizations upon which open source software products are anchored on.

This article is structured as follows. First, prior research into OSSF governance is examined to provide context 


\section{Governance of Open Source Software Foundations: Who Holds the Power?}

\section{Ludovico Prattico}

and background for the research described here. Next, the research method is described, including the definition of "power" that was applied to the context of OSSFs. Then, the results of the artificial neural network analysis of the content of the six foundations' bylaws are presented. Finally, conclusions are provided.

\section{Prior Research in OSSF Governance}

An overview of governance mechanisms uncovered in the studies of open source software development was provided by de Laat (2007; tinyurl.com/a2udonn). The mechanisms include spontaneous governance, internal governance, and "governance towards outside parties". Spontaneous governance is characterized by communities of volunteers who enjoy the intellectual stimulus, have a desire to learn and improve their skillset, or need the code created for their current professional employment or personal use. These communities cross institutional boundaries, are self-directing, and have no formal control. Typically, the de facto leaders are the $20 \%$ that produce $80 \%$ of the code.

The second governance method, internal governance, is related to projects that use explicit and formal tools to co-ordinate and control open source software projects. Internal governance is characterized by six groups of tools: modularization, division of roles, delegation of decision-making, training and indoctrination, formalization, and autocracy/democracy (de Laat, 2007; tinyurl.com/a2udonn).

The third governance method is "governance towards outside parties". This form of external governance is a result of outside parties, such as firms, governments, and non-governmental organizations taking an interest in the benefits of open source software. In order to deal with the challenges associated with creating software in the commons and the threats from patent infringement, this form of governance creates a "legal shell" around the project (de Laat, 2007; tinyurl.com/a2udonn).

O'Mahony (2007; tinyurl.com/cbf2sk5) discusses what it means to be community managed. From research on four large and mature open source software communities, she identified five principles for the communitymanaged governance model: i) independence of any one sponsor; ii) pluralism in diversity of contributors, management of conflict, and determination of leadership; iii) representation where contributing members can be represented in all community decisions; iv) de- centralized decision making (e.g., how contributors gain access to decision-making structures); and v) autonomous participation in that all contributors are welcomed and members contribute on their own terms.

Xie (2008; timreview.ca/article/194) uses the term governance structures to refer to "who participates in the decision making" and concludes that there are three types: i) Merit, ii) Merit Dominated, and iii) Sponsor Dominated. In foundations with Merit governance structures, all members are merit members with full voting rights. In foundations with Merit Dominated governance structures, merit members are the majority, which makes it difficult for sponsor members to affect the outcomes. In foundations with Sponsor Dominated governance structures, sponsored members are typically company employees and would have a greater say in decisions.

This research described in this article builds on the work carried out by Xie (2008; timreview.ca/article/194) by studying the power structures within OSSFs through analyses of their governance documents. More specifically, the research looked at where the power is centred according to the governance documents (bylaws).

\section{Method}

The objective of this research is to study how the management of an OSSF is centred according to the policies set out in its bylaws. In essence, the analysis was a search for the power centres in OSSFs. Power is generally defined as the ability to influence the behaviour of others with or without resistance (Wikipedia, 2012; tinyurl.com/aputt9p). For the purposes of this research, power was defined as the capability of one social actor to overcome a resistance in achieving a desired objective (Pfeffer, 1981; tinyurl.com/amxc9dr). Power has many sources, including delegated authority, social class, material resource, charisma, knowledge, expertise, and so on (Pfeffer, 1981). In addition, French and Raven (1959; tinyurl.com/bfsussh) defines five bases of power: reward, coercive, legitimate, referent, and expert. This research examined legitimate power stemming from internalized values in one social actor, A, that another social actor, B, has a legitimate right to influence and who is obliged to accept the influence of B (French and Raven, 1959).

To examine the power relationships within OSSFs, the bylaws of the same six foundations studied by Xie 


\section{Governance of Open Source Software Foundations: Who Holds the Power?}

\section{Ludovico Prattico}

(2008; timreview.ca/article/194) were analyzed. Following Xie's criteria, to be included in the sample, an OSSF must:

1. Have at least one active open source software project

2. Be incorporated in the United States

\section{Have $501(\mathrm{C})$ tax exempt status}

These criteria ensure that the foundations studied are active, not-for-profit organizations in a common jurisdiction, and are operating under the same laws.

The six foundations selected for analysis were:

1. Apache (apache.org)

2. Eclipse (eclipse.org)

3. GNOME (gnome.org)

4. Plone (plone.org)

5. Python (python.org)

6. SPI (spi-inc.org)

Each of these organizations has its bylaws available for download from its website. Inspection of the documents downloaded showed that, in general, the bylaws of the foundations incorporated the rules on the foundation's management structure, the bylaws and the details of the membership agreement. The bylaws were downloaded from the foundations' respective websites and converted to text format for further analysis.

The bylaws were studied using content analysis (Neuendorf, 2002; tinyurl.com/c7gcrvg), which is also known as discourse analysis (George and Bock, 2011; tinyurl.com/dxnzqol). For text-based documents, content analysis involves studying the language used in the documents to identify patterns in the content. Content analysis can be performed manually, but the process can more efficient and reliable if performed using software. One of the benefits of computer-aided text analysis is that it can be performed without bias arising from the researcher's personal experience and knowledge of the content being analyzed. Because of the textual nature of OSSF bylaws, computer-aided text analysis is well suited for studies such as described here.
There are numerous software applications that perform computer-aided text analysis, mostly stemming from research in the social sciences (Neuendorf, 2002; tinyurl.com/c7gcrvg). The method chosen for this research was artificial neural network analysis (tinyurl.com/yqj9h6), using the Catpac application (tinyurl.com/bcjpzjl). Artificial neural network analysis has been used for qualitative research in various disciplines including business and sociology. Artificial neural network analysis permits the discovery of ideas and recurring concepts in text that are not immediately obvious (Woelfel, 1998; tinyurl.com/a4e79uj), which made it an appropriate tool to use when looking for the power centres in OSSFs.

The following steps were undertaken to analyze the OSSF bylaw text using artificial neural network analysis:

1. A word-count analysis identified words that appear in the documents with high frequency.

2. High-count words that likely would not contribute meaningfully to the analysis were excluded from further analysis. Examples include prepositions, conjunctions, and articles.

3. Dendrograms (hierarchical cluster diagrams) and conceptual maps were created using the Catpac tool. (Examples of each type of visualization are shown in Figures 1 and 2, later in this article.)

4. The relationships between terms that represent governance, such as "Board of Directors", "Chairman", etc. were identified through the analysis of the cluster diagrams and conceptual maps.

\section{Results}

Results of the Catpac analysis were plotted as dendrograms and conceptual maps, which were then used to locate the centres of power for each OSSF. The following two subsections report on results from the analysis of the Eclipse Foundation's bylaws only, to illustrate the process; the dendrograms and conceptual maps used in the analyses of the other foundations are available on request from the author. In the final subsection, the power-centre results for all foundations are described.

\section{Eclipse Foundation dendrogram}

A dendrogram is method to illustrate the arrangement of data that clusters together from the result of performing cluster analysis. In a dendrogram, terms or concepts 


\section{Governance of Open Source Software Foundations: Who Holds the Power?}

\section{Ludovico Prattico}

that appear together in the text under analysis are said to have a stronger relationship than concepts that are not close together. Figure 1 illustrates the dendrogram for the Eclipse Foundation; the output from the Catpac tool is shown in the lower portion of the figure, and a portion of the resulting "tree" is illustrated in the upper portion. Two strong clusters are found around the terms EXECDIREC (Executive Director) and ECLIPSE FOUNDATION. From the first cluster, we note that EXECDIREC has a strong relationship with COMMITTEE, OFFICER, ACTION, and COMMITTER. The SET and FORTH concepts cluster strongly together because they are used heavily in the bylaws in contexts such as "set forth in Section 3.8". This cluster has a strong relationship with EXECDIREC.
In the cluster around the COMMITTEE concept, EXECDIREC has a strong relationship because the Executive Director is involved in setting up committees. For example, in Section 4.1 it reads, "Each committee shall consist of two (2) or more directors nominated by the Executive Director, including ..."

The second major cluster consists of the relationships between a number of other concepts and the ECLIPSE FOUNDATION. This cluster illustrates a close relationship between the concepts of ECLIPSE FOUNDATION and DIRECTORS and the BOARD of DIRECTORS and the work of the foundation in terms of strategic direction and membership.

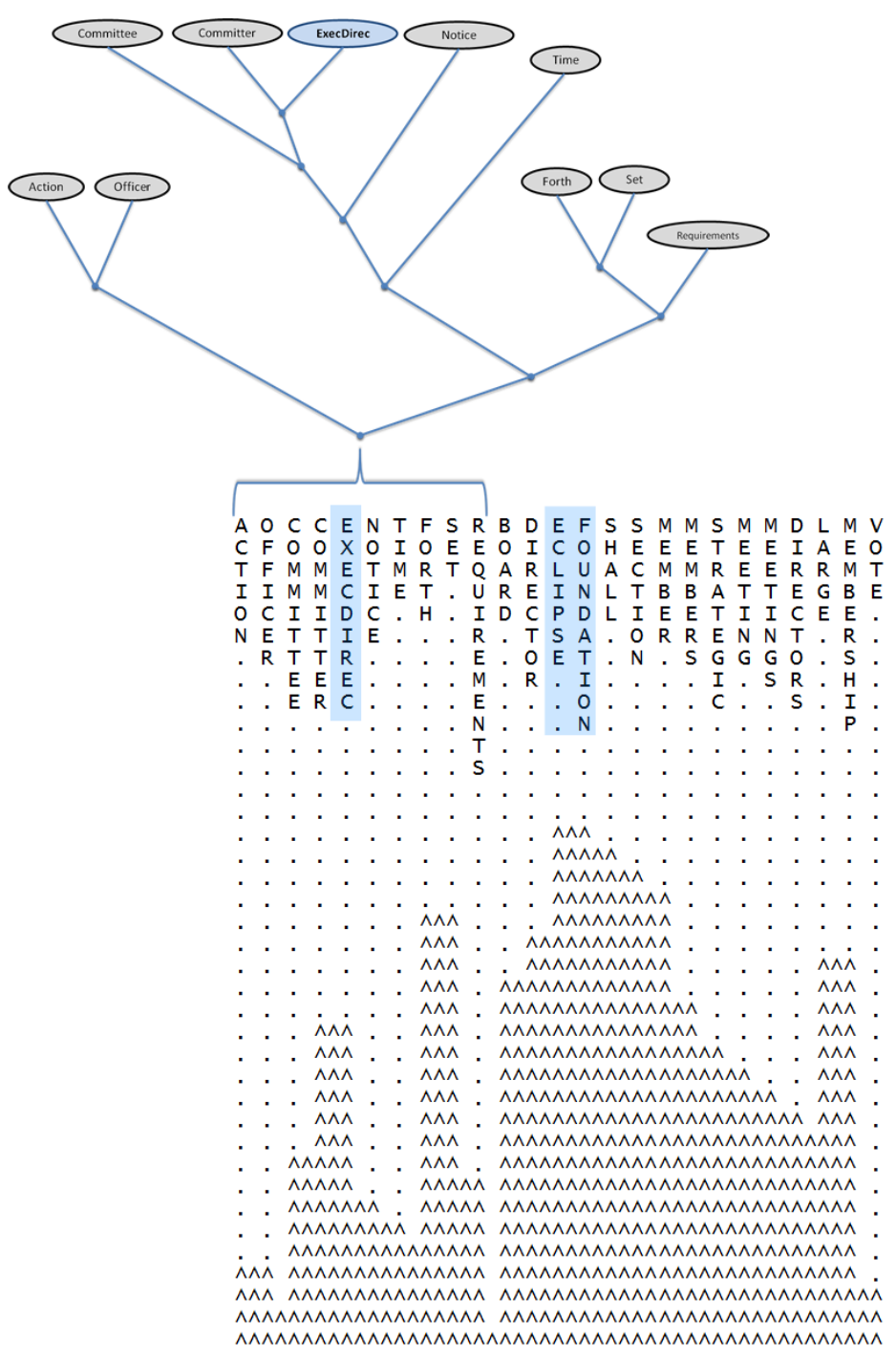

Figure 1. Eclipse Foundation dendrogram 


\section{Governance of Open Source Software Foundations: Who Holds the Power?}

\section{Ludovico Prattico}

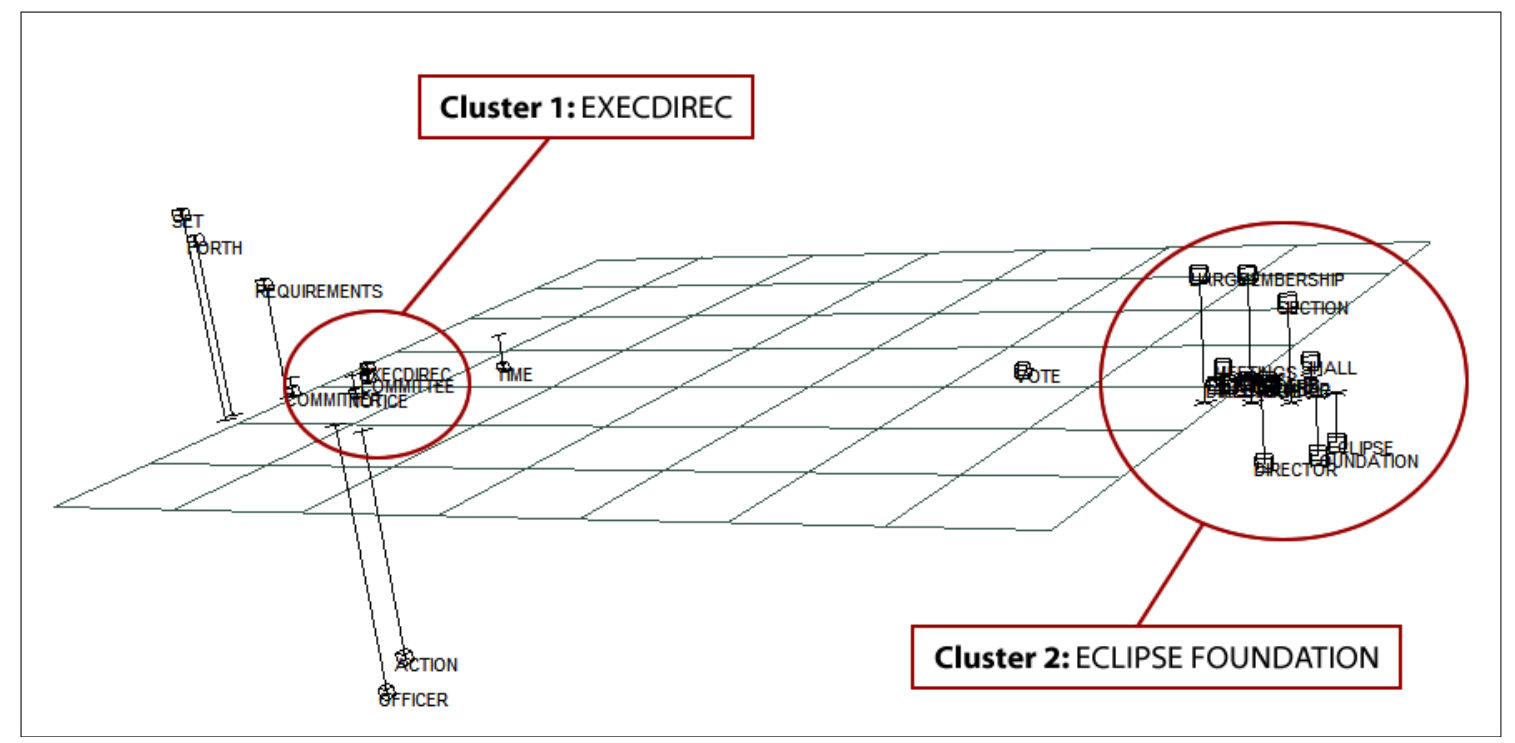

Figure 2. Eclipse Foundation conceptual map

Eclipse Foundation 3D conceptual map

A conceptual map illustrates the same data as the dendrogram except that it provides a three-dimensional view. The closer the terms in the conceptual map, the stronger the relationship between the concepts they represent. What is important is the relative distance between the terms, not their position relative to the plane. The advantage of a conceptual map is that it is three-dimensional; it illustrates the relative relationship strength of all the terms to one another.

The 3D conceptual map in Figure 2 shows two distinctive clusters, Cluster 1 is closely tied to the EXECDIREC term and Cluster 2 is closely tied to the ECLIPSE FOUNDATION, as with the dendrogram. The map clearly shows that the strongest relationships in managing the foundation are related to the Executive Director.

\section{Centres of power for all six foundations}

The content analysis showed that power in an OSSF is distributed across three groups: i) Members, ii) Chairman/President/Executive Director, iii) and Board of Directors. Thus, the relationships described in the previous subsections can be illustrated in a triangular diagram whose apexes represent these three groups (Figure 3). In the diagram, the power centre of each of foundation was plotted based on the results from the analysis of the dendrograms and conceptual maps for each OSSF.

As Figure 3 shows, the management-related functions in the Eclipse Foundation cluster around the Executive Director. In the case of the Apache Foundation, the Board of Directors has the majority of the power with a skew towards the Members and away from the Chairman/President. The same holds true for the Plone Foundation. However, the power is skewed a little farther away from the Chairman/President than for the Apache Foundation. In the case of the Python Foundation, the power is squarely on the Board of DirectorsMembers axis. In the case of the Eclipse Foundation, power lies clearly with the Chairman/President (in this case the Executive Director). In the case of the GNOME and SPI Foundations, the power is more centered with a skew towards the Board of Directors and Members.

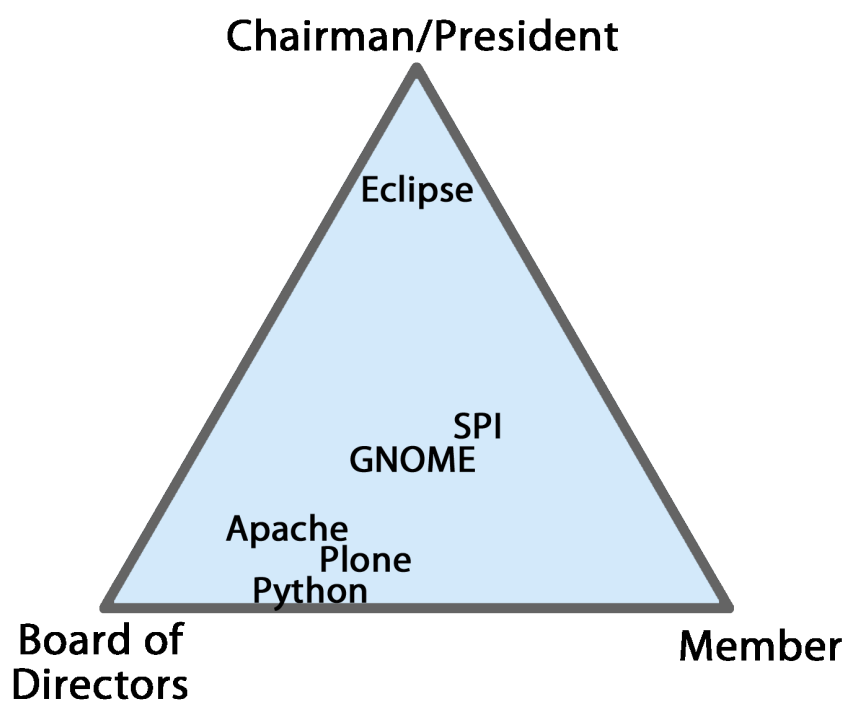

Figure 3. The power centres of six open source software foundations 


\section{Governance of Open Source Software Foundations: Who Holds the Power?}

\section{Ludovico Prattico}

\section{Conclusion}

Three conclusions can be drawn from this study:

1. Computer-aided text analysis of OSSF bylaws demonstrated that the actions of an open source software foundation are centered on one of three groups: Members, Chairman/President/Executive Director, and Board of Directors. However, this research did not study why power lies within different groups of a given foundation.

2. The majority of the literature on OSSF governance focuses on the mechanisms and processes used to manage OSSFs. This work touches on one aspect of how OSSFs are managed through the application of the bylaws, but more work is needed to see how the bylaws impact the management of the OSSFs.

3. Artificial neural network analysis of OSSF bylaws provides unbiased insights on the power structure of OSSFs. Each bylaw uses its own language, thus causing the researcher to interpret results based on the bylaw's unique language. This can be improved upon by creating a standardized dictionary of term that map terms used in a given bylaw with a standardized term. For example, all the terms for the highest office (President, Chairman, Executive Director, etc.) would be mapped into the term EXECDIREC.

Finally, this research showed that the power in OSSFs lies within different groups, but provided no insight on why this is the case. Further studies into the underlying reasons for the power distributions observed in this study would contribute to a better understanding of how OSSFs operate and how they can be organized to provide greater benefit to their members.

\section{About the Author}

Ludovico Prattico is a recent graduate of the Technology Innovation Management program at Carleton University in Ottawa. In addition to his Master's degree research at Carleton, he oversaw the operations, external content, and overall support of the Carleton Entrepreneurs program and recruitment of candidates for the Lead To Win program. Previously, he worked at Nortel Networks and BellNorthern Research, where he led the Optical Networks architecture and standards development team, and the high capacity OC-48 hardware team with the responsibility for the development and introduction of the dense wavelength division multiplexing product. Mr. Prattico also holds a Bachelor of Engineering (Electrical) degree from McGill University.

Citation: Prattico, L. 2012. Governance of Open Source Software Foundations: Who Holds the Power? Technology Innovation Management Review. December 2012: 37-42. (cc) BY 